\title{
Logística Reversa Orientada para a Inovação nas Micro e Pequenas Empresas: um estudo exploratório
}

\author{
Innovation-Oriented Reverse Logistics in Micro and Small Enterprises: \\ an exploratory study
}

\author{
Yris Raquel Santos de Santana ${ }^{1}$ \\ André Luís Rocha de Souza ${ }^{1}$ \\ Ângela Maria Ferreira Lima ${ }^{1}$ \\ Márcio Luis Valença Araújo ${ }^{1}$ \\ ${ }^{1}$ Instituto Federal de Educação, Ciência e Tecnologia da Bahia (IFBA), Salvador, BA, Brasil
}

\begin{abstract}
Resumo
O objetivo desse artigo foi investigar a logística reversa como alicerce para práticas inovadoras nas Micro e Pequenas Empresas brasileiras. Para tal, utilizou-se a metodologia de caráter exploratório, teórico, e abordagem qualitativa, cuja técnica de investigação utilizada foi a pesquisa bibliográfica. A partir dos estudos foi possível compreender que, se bem gerenciada, a inserção da inovação no processo logístico reverso nas Micro e Pequenas Empresas é capaz de potencializar a competitividade entre elas, frente a uma tendência e demanda do mercado. Como resultado, foi elaborada uma análise sobre os possíveis fatores que poderiam determinar forças, fraquezas, ameaças e oportunidades na aplicação da Logística Reversa orientando a inovação nessas empresas. Espera-se que esse trabalho dê subsídios para que esse segmento de empresas possa vislumbrar a possibilidade de inovar nas práticas, processos, produtos e outros, por meio do gerenciamento sustentável.
\end{abstract}

Palavras-chave: Logística Reversa. Inovação. Micro e Pequenas Empresas.

\begin{abstract}
The purpose of this paper was to investigate reverse logistics as a foundation for innovative practices in Brazilian Micro and Small Enterprises. For that, we used the methodology of exploratory character, theoretical, and qualitative approach whose research technique used was bibliographic research. From the studies it was possible to understand that, if well managed, the insertion of innovation in the reverse logistics process in Micro and Small Enterprises is capable of enhancing the competitiveness between them, facing a market trend and demand. As a result, an analysis was made of the possible factors that could determine strengths, weaknesses, threats and opportunities in the application of Reverse Logistics guiding innovation in these companies. It is hoped that this work will provide subsidies for this segment of companies to envisage the possibility of innovating in practices, processes, products and others through sustainable management.
\end{abstract}

Keywords: Reverse Logistics. Innovation. Micro and Small Business.

Área Tecnológica: Desenvolvimento. Inovação. 


\section{Introdução}

Assuntos alusivos a questões ambientais vêm ganhando notoriedade não só pelas evidências científicas, mas principalmente no que se refere à exigência por parte dos consumidores em relação ao que está sendo ofertado no mercado. Empresas estão cada vez mais se adequando às questões socioambientais por meio de uma responsabilidade social que permite a elas a fidelização de clientes, agregar valor à marca, além de promover um crescimento comercial (LACERDA; MOURA, 2016).

Segundo Zanatta (2017), as preocupações sobre desenvolvimento sustentável são recentes, pois foi só na década de 80 que as pessoas perceberam que a base dos problemas ambientais estava diretamente ligada ao desenvolvimento econômico e à preservação ambiental. Assim, houve a necessidade de promover uma atitude protecionista sobre os aspectos ambientais $e$ buscar o desenvolvimento sustentável.

Reflexo disso é a Lei n. 12.305/2010, da Política Nacional de Resíduos Sólidos (PNRS). Seu principal objetivo é a implementação de uma responsabilidade compartilhada pelo ciclo de vida dos produtos entre o setor privado, o poder público e a sociedade civil. Além disso, evidencia a importância da reutilização e reciclagem, bem como o retorno da matéria-prima ao processo produtivo, ou seja, existe uma preocupação quanto à recuperação, reciclagem e descarte correto de materiais. Isso demonstra que existe uma tendência, sobretudo pela legislação ambiental, para cada vez mais tornar as empresas responsáveis pela totalidade do ciclo de vida do produto.

Em consonância, a Organização das Nações Unidas (ONU), em 2015, reuniu chefes de Estados e Governos e promulgou a Agenda 2030, que "é um plano de ação para as pessoas, para o planeta e para a prosperidade" (ONU, 2015). Tal agenda inclui os Objetivos de Desenvolvimento Sustentáveis (ODS), que propõem uma coordenação entre governos, empresas, academias e sociedade civil a fim de alcançar os 17 objetivos e suas 169 metas, promovendo assim uma vida digna para todos.

Entre os 17 objetivos, destaca-se aqui o objetivo 12 - Assegurar padrões de produção e de consumo sustentáveis - que, de modo geral, pretende priorizar a informação, gestão coordenada e a responsabilidade para os consumidores sobre a utilização dos recursos naturais, a fim de auxiliar na busca de padrões mais sustentáveis de produção e consumo. Nesse sentido, algumas de suas metas pretendem: promover o melhor manejo para os produtos químicos e resíduos, diminuir a geração de resíduos e, assim, incentivar práticas sustentáveis como a prevenção, reciclagem e reúso, além do incentivo sobre a adoção de práticas sustentáveis nas empresas (ONU, 2015).

É nesse contexto que a Logística Reversa (LR) torna-se um assunto importante. Para Wille e Born (2013), a Logística Reversa propõe um melhor aproveitamento do produto em todo o seu processo produtivo. Assim, é capaz de tornar a empresa mais competitiva pela transformação de produtos descartados em novos itens, ou até mesmo pela oferta de preços mais competitivos, mostrando ao consumidor que a empresa está envolvida em questões socioambientais, além de proporcionar uma imagem sólida, segura e credível no cenário social e mercadológico.

Dessa forma, a Logística Reversa sugere uma maneira mais eficiente sobre a gestão dos produtos, sendo responsável por nortear uma responsabilidade compartilhada entre empresa e consumidor. Ainda segundo Wille e Born (2013), a temática abordada é importante sob a 
ótica de que a "vida útil" de um produto não se encerra quando este é entregue ao cliente, até porque todo produto pode tornar-se obsoleto, danificado, pode não funcionar mais e, para isso, é necessário fazer o descarte corretamente ou, em alguns casos, sofrer efeito de reparação ou reaproveitamento.

O SEBRAE (2012) realizou uma pesquisa com 3.912 pequenos e microempresários brasileiros e apurou que já existe uma forte tendência para práticas sustentáveis. Contudo, a maior dificuldade observada é fazer com que cada vez mais empresas desse porte introduzam em suas práticas gerenciais e estratégias de mercado uma proposta sustentável.

Vale salientar que, nos últimos 30 anos, as Micro e Pequenas Empresas (MPE) vêm desempenhando um papel extremamente importante no crescimento do país, principalmente, no tocante ao aspecto socioeconômico em que elas desempenham suas atividades (SEBRAE, 2014). A inovação também é um dos principais responsáveis para o sucesso e permanência dessas empresas, tanto que a competitividade entre elas (MPE) fomenta o desenvolvimento do país (MAIA, 2012).

Para Dias (2012), existem alguns motivos que devem ser levados em consideração pelas MPE sobre a importância de se desenvolver práticas sustentáveis como: a cobrança em desenvolver uma sociedade mais consciente, as exigências geradas pelas empresas de grande porte e a competitividade existente no setor público (por meio de seu poder de compra).

Dessa forma, o presente estudo visa à possibilidade de compreender a atuação dessas empresas, por meio de diretrizes previstas na lei vigente (PNRS) e como esta pode ser fator preponderante para as práticas inovadoras de gerenciamento dos resíduos sólidos nas MPE inseridas no mercado nacional brasileiro. Segundo Tachizawa e Andrade (2008), quanto mais cedo os empresários adotam a sustentabilidade em seus negócios como fator de desafio e oportunidade competitiva, maiores são as chances de o negócio sobreviver no mercado.

Posto isso, apresenta-se o seguinte questionamento: A Logística Reversa pode ser indutora de práticas inovadoras nas Micro e Pequenas Empresas brasileiras? A partir desse pressuposto, o presente artigo objetivou investigar a Logística Reversa como alicerce para práticas inovadoras nas Micro e Pequenas Empresas nacionais.

Esse artigo está dividido em cinco seções, a saber: 1) Introdução, apresentando relevância do tema, a justificativa, questão norteadora e objetivo; 2) Referencial Teórico, que fundamenta o trabalho; 3) Procedimento Metodológico; 4) Avaliação e Discussão dos Resultados encontrados e, finalmente, 5) a Conclusão sobre essa pesquisa e sugestões para futuros trabalhos.

\section{Referencial Teórico: logística, logística verde e logística reversa}

A logística pode ser considerada uma importante estratégia de gestão dos fluxos dos materiais dentro da cadeia produtiva. Atualmente, se mostra como uma grande área de estudos dentro das organizações modernas, pois confere às empresas que usufruem de bons sistemas de gestão de logística maiores vantagens competitivas frente aos concorrentes.

Assim, a logística pode ser definida como um conjunto de cinco atividades: aquisição, movimentação, armazenagem, entrega e descarte; devendo guiar-se pelo princípio de estar "no local certo, na hora certa e ao menor custo possível" (PEREIRA; WELZEL; SANTANA, 2011). 
Já a Logística Verde complementa de forma integrada as atividades de Logística sob a perspectiva dos aspectos e impactos que esta propicia à sociedade e ao meio ambiente. Sendo assim, seu principal objetivo é fomentar as práticas das atividades inerentes à cadeia de suprimentos de modo a gerar o menor custo para o meio ambiente (SANTOS et al., 2015).

Para Santos et al. (2015), são inúmeras as razões que podem levar uma empresa a praticar a Logística Reversa como, por exemplo, o fato de melhorar a reputação e proteger a marca através de uma mensagem construída pelo aparato ambiental. Isso se explica pela crescente conscientização ambiental por parte dos consumidores, e a adoção de práticas "verdes" pode proporcionar vantagens competitivas e aumento de demandas, já que os consumidores estão preferindo os produtos ecologicamente corretos e que gerem menos impactos ao meio ambiente, e se mostram dispostos a pagar mais caro por esses tipos de produtos.

Assim sendo, a Logística Reversa (LR) pode ser considerada como uma subárea da Logística e nos últimos anos vem ganhando importância, principalmente, pelo crescimento de resíduos produzidos, em maior parte, nos grandes centros urbanos.

A legislação brasileira possui uma definição clara e abrangente sobre a LR:

[...] instrumento de desenvolvimento econômico e social caracterizado por um conjunto de ações, procedimentos e meios destinados a viabilizar a coleta e a restituição dos resíduos sólidos ao setor empresarial, para reaproveitamento, em seu ciclo ou em outros ciclos produtivos, ou outra destinação final ambientalmente adequada (BRASIL, 2010, art. 1).

A LR trata dos aspectos que envolvem o retorno do produto, embalagens e materiais ao centro produtivo, ou seja, trata-se do caminho inverso da cadeia produtiva da logística tradicional sendo que, neste caso, o produto tem como ponto de partida os consumidores e como destino os fabricantes (WILLE; BORN, 2013).

Para melhor compreensão da LR, faz-se necessária a diferenciação entre ela e a gestão de resíduos sólidos:

A gestão integrada dos resíduos sólidos inclui todas as ações voltadas à implementação de soluções, procedimentos e regras. O maior desafio desse processo é a articulação entre os entes federativos e os demais atores sociais envolvidos no manejo dos resíduos sólidos. A elaboração dos planos nacional, estaduais, microrregionais, intermunicipais, municipais e os de gerenciamento de resíduos sólidos é um componente fundamental para a gestão integrada. Esses planos, de responsabilidade dos entes federados - governos federal, estaduais e municipais - devem tratar de questões como: coleta seletiva, reciclagem, inclusão social e participação da sociedade civil (BRASIL, 2014, p. 12).

Por conseguinte, a gestão de resíduos sólidos abrange uma rede de atividades mais ampla, composta por todas as áreas da gestão da organização. Já a Logística Reversa trata da gestão do fluxo dos materiais, ou seja, é a gestão do transporte, coleta e controle do fluxo do material e dos produtos no fim do ciclo de vida.

Segundo Gonçalves, Tanaka e Amedomar (2013), a LR pode ser resumida como o processo que depende de uma gestão adequada dos canais de distribuição, do ponto de consumo até o ponto de origem, tendo como objetivo a recuperação do valor ou o tratamento apropriado dos resíduos sólidos gerados. 
De acordo com Leite (2009), existem duas grandes áreas de atuação da LR: Pós-venda e Pós-consumo. Os bens do Pós-consumo são aqueles que não têm mais nenhuma utilidade para a sociedade. Mesmo depois de utilizados extensivamente e, por fim, descartados, mesmo ainda em condição de uso, chegam ao final da sua vida útil, seja pelo desinteresse do consumidor ou pela inutilização do mesmo. Um exemplo de Pós-consumo é quando um pneu que já chegou ao fim da vida útil é transformado em insumo para fabricação de asfalto.

Por outro lado, a Logística de Pós-venda é o fluxo logístico que se encarrega de produtos que não foram usados, ou usados minimamente, porém que, por alguma razão, retornam à cadeia de distribuição direta. Seu objetivo é reintegrá-lo ao mercado para que seja novamente consumido. O produto é coletado, em seguida é feito o reparo ao dano que o tirou do mercado, para assim comercializá-lo outra vez. Um exemplo de Pós-venda é quando são comercializados, em grandes feiras, produtos com pequenas avarias por um preço menor proporcional ao dano/ defeito.

\subsection{Gerenciamento da Cadeia de Suprimentos Reversa}

A Cadeia de Suprimentos pode ser entendida como uma rede de organizações, pessoas, atividades, recursos, informações e tudo que estiver envolvido na atividade que compreende o transporte de um produto ou serviço, dos fornecedores até os clientes finais. Para Ballou (2004), a gestão da cadeia de suprimentos permeia a interação da logística, funções de marketing e a área de produção da empresa.

Assim, o gerenciamento da cadeia de suprimentos associada à LR torna-se uma prática de fundamental importância para as empresas, pois permite que ao ser descartado pelo consumidor, o produto seja incorporado a uma nova cadeia de suprimento que será responsável por coletar, processar e entregar o mesmo aos recicladores, que terão a função de incorporá-lo novamente ao mercado; e caso não seja possível, deverá ser feito o seu descarte correto.

Uma estratégia para melhorar o gerenciamento, é a utilização de Ecopontos, que são contentores ou alojamentos provisórios feitos pelas empresas para que os consumidores tenham um local específico para depositar determinado material quando a vida útil deste chega ao seu fim. Com isso, o cliente teria a comodidade de ter onde eliminar o resíduo e a empresa conseguiria transportar um maior número de material, reduzindo assim o custo de coleta.

\subsection{Lei n. 12.305 - Política Nacional de Resíduos Sólidos (PNRS)}

Em agosto de 2010 foi sancionada a Lei Federal n. 12.305, a qual se refere à Política Nacional de Resíduos Sólidos (PNRS). Essa lei institui a implementação da responsabilidade compartilhada pelo ciclo de vida dos produtos entre o setor privado, o poder público e a sociedade civil:

É instituída a responsabilidade compartilhada pelo ciclo de vida dos produtos, a ser implementada de forma individualizada e encadeada, abrangendo os fabricantes, importadores, distribuidores e comerciantes, os consumidores e os titulares dos serviços públicos de limpeza urbana e de manejo de resíduos sólidos, consoante às atribuições e procedimentos previstos nesta Seção. (BRASIL, 2010, Art. 30) 
Para Leite (2009), os estudos e a relevância do tema LR têm ganhado importância e crescimento por conta da legislação ambiental, uma vez que esta diminui a responsabilidade do governo e passa a obrigar as empresas ou suas cadeias industriais a disporem de fluxos reversos para produtos de Pós-venda e Pós-consumo.

Portanto, a PNRS reforça a importância da LR não só no aspecto ambiental, mas, principalmente, nos âmbitos social e econômico. Como ferramenta de desenvolvimento para tais aspectos, reúne um conjunto de ações, procedimentos e meios com o intuito de viabilizar a coleta, o reaproveitamento, a restituição ou quaisquer outros meios de destinação derradeira ambientalmente adequada.

Diante disso, é possível considerar que a PNRS pode proporcionar vários benefícios como, por exemplo, a inclusão social através do fortalecimento das cooperativas de catadores, e o incentivo à indústria de reciclagem, uma vez que, em ambos os exemplos, a PNRS, por meio de suas diretrizes, conduz a coleta seletiva e a educação ambiental, além de fomentar a articulação dos incentivos financeiros, fiscais e sociais (MMA, 2019).

Logo, a PNRS parte da premissa da responsabilidade compartilhada, ou seja, traz obrigações inerentes a todos os envolvidos na LR dos produtos em fim de vida útil. Nesse sentido, o consumidor é peça fundamental, pois o descarte de produtos e resíduos parte em primeira instância dele, sendo ele o responsável por decidir o descarte do produto de maneira apropriada ou jogá-lo no meio ambiente.

No entanto, a tomada de decisão errada por parte do consumidor pode estar diretamente relacionada ao acesso à informação, ou melhor, à falta dela pelos diversos atores envolvidos no processo reverso, destacando-se aqui os varejistas e fabricantes. Sem contar que muitas organizações não dispõem de uma estrutura adequada para praticar a LR, o que, consequentemente, não gera o incentivo da empresa para o consumidor em fazê-la (LR).

\subsection{As Micro e Pequenas Empresas (MPE)}

Cada vez mais os consumidores estão demandando produtos e serviços oriundos de práticas sustentáveis e ambientalmente corretas. É uma tendência estimulada pelo próprio mercado, e que vem ganhando força, sobretudo, pelo desenvolvimento econômico e socioambiental que elas proporcionam. Nesse cenário, as MPE vêm se posicionando de forma crescente, aderindo à tendência do mercado e exigências legais (POZO; AKABANE; SILVA, 2013).

Por possuírem menos recursos e pouca habilidade gerencial, as MPE enfrentam algumas dificuldades para colocarem em prática ações decorrentes das tendências de mercado (SANTOS et al., 2007). Mesmo diante dessa realidade muitas dessas empresas estão incorporando práticas da gestão ambiental (DIAS, 2007).

Por ter relação direta com a gestão ambiental, a LR pode contribuir de forma significativa para as MPE gerenciarem práticas ambientais, possibilitando as oportunidades de negócios, inovação e desenvolvimento econômico quando o assunto for reciclagem, redução e reutilização de produtos e matérias.

São criados anualmente mais de 1,2 milhão de novos empreendimentos formais e, desse total, $99 \%$ são representados pelos Empreendedores Individuais (EI) e MPE, que são responsáveis por gerar mais da metade dos empregos com carteira assinada do país. Sem contar que as MPE 
contribuem significativamente para o PIB Brasileiro, e são tão importantes para a economia que cada vez mais se busca compreender como funcionam e conhecer as legislações que ajudam no seu fortalecimento para que cada vez mais se tornem competitivas (SEBRAE, 2011).

Segundo Rocha e Simonetti (2008), no caso do Brasil existem quatro maneiras de classificar uma empresa levando-se em consideração as características e particularidades da organização. Assim, elas podem ser: micro, pequenas, médias ou grandes. Mas a legislação brasileira, na Lei Complementar n. 123, de 14 de dezembro de 2006, define e classifica as MPEs como:

Art. $3^{\circ}$ - Para os efeitos desta Lei Complementar consideram-se microempresas ou empresas de pequeno porte, a sociedade empresária, a sociedade simples, a empresa individual de responsabilidade limitada e o empresário a que se refere o Art. 966, da Lei no 10.406, de 10 de janeiro de 2002 (Código Civil), devidamente registrados no Registro de Empresas Mercantis ou no Registro Civil de Pessoas Jurídicas, conforme o caso, desde que:

I - no caso da microempresa aufira, em cada ano-calendário, receita bruta igual ou inferior a $\mathrm{R} \$ 360.000,00$ (trezentos e sessenta mil reais); $e$

II - no caso de empresa de pequeno porte aufira, em cada ano-calendário, receita bruta superior a $\mathrm{R} \$ 360.000,00$ (trezentos e sessenta mil reais) e igual ou inferior a $\mathrm{R} \$$ 4.800.000,00 (quatro milhões e oitocentos mil reais). (BRASIL, 2016)

Outro parâmetro de classificação das MPEs é a quantidade de pessoas que trabalham nessas empresas. Esse tipo de classificação é muito utilizado pelo Serviço Brasileiro de Apoio às Micro e Pequenas Empresas (SEBRAE), conforme demonstrado na Tabela 1.

Tabela 1 - Classificação das MPEs por número de empregados

$\begin{array}{ccc}\text { Porte/Setor } & \text { Comércio E Serviço } & \text { Indústria } \\ \text { Microempresas } & \text { Até } 9 & \text { Até } 19 \text { empregados } \\ \text { Empresas de Pequeno Porte } & \text { De } 10 \text { a } 49 & \text { De } 20 \text { a } 99 \text { empregados }\end{array}$

Fonte: Adaptada de SEBRAE-SP (2015)

Visando a trazer maior proteção aos empreendedores, em 2006 foi criada uma lei específica para os micro e pequenos negócios, conhecida no meio jurídico como Lei Geral, que foi baseada na Lei Complementar Federal n. 123/2006, com uma atualização para Lei n. 154/2016, a qual garante uma série de benefícios, deveres e direitos aos empreendedores.

O principal objetivo da lei é quebrar barreiras que impedem o desenvolvimento dos pequenos negócios, sendo que seu intuito é proporcionar um tratamento simplificado, diferenciado e favorável nas áreas mercadologias, burocráticas, legalizações de documentos e, principalmente, nas tributações aos pequenos negócios proporcionando, assim, o fortalecimento e a competitividade entre eles.

O fato de haver uma lei específica para as MPEs só corrobora para que no Brasil essas empresas detenham importância não só no cenário econômico, mas também no cenário socioambiental. Além disso, a Lei Geral das MPEs incentiva o desenvolvimento dessas empresas pela desburocratização em alguns processos, ou seja, a lei facilita a vida desses empreendedores ajudando-os a participarem de licitações públicas, ampliando e facilitando as linhas de créditos e outros. 


\subsection{Inovação}

A inovação é um conceito muito abordado no meio acadêmico e, principalmente, empresarial visto que as contínuas mudanças na economia demandam que as empresas, independentes do seu porte, procurem por melhores alternativas para suprirem determinadas necessidades do mercado, que está cada vez mais exigente.

Assim, a atual conjuntura econômica do mercado brasileiro baseia-se na inovação como elemento fundamental para a sobrevivência e estabilização em um mercado dinâmico e altamente competitivo. Desta forma, a inovação acaba sendo ferramenta de empreendedores que vislumbram a transformação das mudanças do mercado em oportunidades para diferentes negócios, produtos e serviços (Instituto de Pesquisa Econômica Aplicada - IPEA, 2017).

Segundo Schumpeter (1988), a inovação tecnológica permite desenvolver uma quebra no sistema econômico, proporcionando um desequilibrio que é capaz de alterar a formas de padrões de produção, e desenvolvendo uma diferenciação para a empresa, sendo a inovação, o ponto central para o desenvolvimento econômico de uma região, estado ou país.

Assim, a inovação é elemento propulsor do crescimento de um mercado. Tanto que, para Drucker (1986), a inovação consiste no ato de incorporar novas capacidades aos recursos (processos e pessoas) que existem na empresa com o intuito de gerar riquezas. Já para Girardi (2001), é resultado da criatividade que as empresas empregam ao gerir todos os seus processos. Nesse sentido, vale salientar que para ser considerado inovação, o produto ou método deve ser novo ou incrementado com atributos que superem os já existentes (OCDE, 2005).

Partindo-se desse pressuposto, a satisfação do cliente pode ser incorporada como atributo na inovação, pois é possível considerar a criação de valores distintos e superiores em qualidade para os clientes, em detrimento dos concorrentes. O fato é que, de modo geral, as organizações inovam quando pretendem melhorar seu desempenho, por exemplo, pelo aumento da demanda ou redução dos custos. Logo, objetivam defender sua posição competitiva e angariar novas vantagens no mercado em que estão inseridas, tratando a inovação como estratégia para a sua sobrevivência no mercado (OCDE, 2005), ou seja, um dos principais objetivos da inovação é oferecer aos clientes soluções superiores às que já se ofereciam, sempre agregando mais valor ao novo produto ou serviço.

Alguns autores tendem a definir inovação nas empresas de acordo com o porte delas. Schumpeter (1988), por exemplo, comparou a intensidade da atividade de inovação ao porte das empresas, dessa forma, quanto maior a empresa, maior será sua intensidade inovativa.

Isso leva a pensar que quanto maior o porte de uma empresa, maior é seu nível de desenvolvimento de atividades, produtos, processos, serviços inovadores, considerando-se o fato de que, além de porte menor, as MPEs não dispõem de ativos complementares para explorar a inovação em sua rotina gerencial. Contudo, Cruz (2003) reintegra que as MPEs, em relação às grandes empresas, possuem alto poder de inovação, e isso se explica pela sua enorme capacidade de se adaptarem com rapidez às demandas de mercado.

Apesar dessa discussão quanto à inovação estar diretamente relacionada ao porte da empresa, é preciso considerar que tornar-se inovador reúne uma série de características como, por exemplo, estabelecer estratégias de mercado, ter uma estrutura consolidada quanto à força de trabalho, saber estabelecer alianças com outras organizações. 
Teixeira, Neto (2011), em seus estudos, verificou que no Brasil as empresas de pequeno porte são extremamente importantes para o desenvolvimento socioeconômico nacional. E é nesse contexto que a LR pode se tornar fator preponderante para fortalecer ainda mais as MPEs, se vislumbrar o teor inovativo e as possibilidades de desenvolvimento atrelado à prática dessa atividade. A inovação integrada ao processo de LR pode contribuir para o desenvolvimento de estratégias organizacionais; desenvolvimento competitivo; minimizar custos, além de ajudar a reduzir ou até mesmo evitar impactos causados ao meio ambiente.

\section{Metodologia: caracterização da pesquisa}

Para atingir o objetivo dessa pesquisa, foi utilizada a metodologia exploratória por meio de uma abordagem qualitativa, cuja técnica escolhida foi revisão bibliográfica.

Segundo Vergara (2000), a pesquisa bibliográfica consiste no "estudo sistematizado desenvolvido com base em material publicado em livros, revistas, jornais, redes eletrônicas, isto é, material acessível ao público em geral. Fornece instrumental analítico para qualquer outro tipo de pesquisa".

Assim, para a realização deste trabalho, o caráter exploratório e bibliográfico constroi-se a partir da identificação dos campos de estudo (LR, MPEs e Inovação) e de um levantamento dos autores que tratam do tema para compor o referencial teórico, dando embasamento à análise.

A pesquisa configura-se como exploratória, pois o foco está no aprofundamento sobre o conteúdo e na descoberta de como a LR pode orientar a inovação proporcionando o crescimento e desenvolvimento das MPEs.

A pesquisa qualitativa utiliza informações que não podem ser quantificadas. Logo, o foco é estabelecer uma compreensão e explicação da LR. Para Minayo (2001), a pesquisa qualitativa permeia a compreensão dos significados, motivos, crenças, valores e atitudes, ou seja, permite um entendimento acerca dos processos e efeitos que não podem sintetizar a operacionalização de variáveis.

Desta forma, a presente pesquisa é qualitativa porque visa a entender os aspectos sociais, culturais, e econômicos que estão envolvidos nessa nova concepção sobre gerenciamento da inovação nas práticas da LR nas MPEs.

$\mathrm{Na}$ tentativa de responder à questão que norteia essa pesquisa, a saber: A logística reversa pode ser indutora de práticas inovadoras nas Micro e Pequenas Empresas brasileiras?, bem como alcançar seu objetivo, é que a análise da matriz "Strengths, Weaknesses, Oportunities, Threats" (SWOT) foi utilizada, através da qual se buscou identificar forças, fraquezas, ameaças e oportunidade inerentes à prática da LR.

Vale salientar que foram levadas em consideração as evidências científicas e aspectos da lei da PNRS na tentativa de elucidar possíveis fatores que poderiam ser utilizados para compor a análise SWOT. Foi necessário evidenciar, na análise, o estudo realizado pelo SEBRAE em 2012: "O que pensam as Micro e Pequenas Empresas sobre Sustentabilidade", o que proporcionou uma compreensão reflexiva acerca da temática sustentabilidade nas MPEs, contribuindo para corroborar a importância do tema em estudo e a contextualização para a elaboração da matriz SWOT. 
Tal abordagem justifica-se como base para a construção de um raciocínio crítico e reflexivo que a pesquisa científica proporciona.

\subsection{Procedimentos e Etapas}

Para alcançar o objetivo proposto nesta pesquisa: "investigar a logísticas reversa como alicerce para práticas inovadoras nas Micro e Pequenas Empresas nacionais", foram percorridas as seguintes etapas.

A primeira etapa compreende todo o estudo exploratório realizado com o intuito de fazer o levanto do aparato teórico que pudesse ser utilizado como desenvolvimento na revisão da literatura. Para tal, foram elencados autores, artigos, dissertações, relatórios técnicos e bases legais elaborados a respeito de cada campo de estudo (LR, MPE e Inovação) isoladamente e, posteriormente, a inter-relação entre os mesmos.

Na segunda etapa, foi realizada uma filtragem de todo o material encontrado que fizesse uma relação congruente e direta entre os campos de estudos, o que possibilitou uma percepção maior sobre a interação entre as temáticas abordadas (LR, MPE e Inovação). Para tal foi feita uma busca de artigos que, em sua maioria, utilizaram a técnica de análise de estudos de casos, abordando a LR como elemento agregador no processo de inovação, os quais demonstraram a interação entre os temas (LR, MPE e Inovação).

Dessa forma, os artigos serviram para fornecer maior entendimento de como a LR pode impactar no processo de inovação nas empresas, especificamente nas MPEs. Para isso, não foi utilizada como fonte de pesquisa nenhuma base de banco de dados específica, pois, o objetivo não era fazer um estudo bibliométrico e, sim, ter uma compreensão sobre tema, por meio de exemplos práticos e reais. Isso contribuiu na identificação de características que pudessem justificar o motivo pelo qual a LR pode ser orientada para a inovação nas Micro e Pequenas Empresas, auxiliando na construção da análise SWOT.

Em relação à terceira etapa, realizou-se a pesquisa do material bibliográfico (base teórica e relatório técnico do SEBRAE) levantado, por meio de uma análise contextual, crítica e comparativa com a legislação (PNRS), a fim de desenvolver argumentos que pudessem sustentar os pontos evidenciados como "força", "fraqueza", "ameaça" e "oportunidade", que compuseram toda a análise desse estudo, o que culminou na elaboração da Figura 1.

Após concluir a terceira etapa, buscou-se na quarta etapa elaborar as considerações finais, por meio do desenvolvimento de uma argumentação conclusiva, crítica e reflexiva a respeito da temática abordada.

\section{Resultados e Discussões}

O SEBRAE, em 2012, realizou um estudo intitulado "O que pensam as Micro e Pequenas Empresas sobre Sustentabilidade? ", o qual buscou avaliar o nível de percepção dos micro $e$ pequenos empresários brasileiros a respeito da sustentabilidade. No total, foram entrevistados 
cerca de 3.912 empresários do país. O estudo revelou que as MPEs vêm desenvolvendo forte tendência para gerenciar e desenvolver práticas sustentáveis. Apesar disso, cerca de $54 \%$ dos empresários, segundo o estudo, não percebem essas práticas como uma oportunidade de ganho.

Segundo o SEBRAE (2012), o estudo ainda revelou que:

a)Em relação ao nível de conhecimento sobre sustentabilidade e meio ambiente $65 \%$ dos entrevistados demonstraram conhecimento e apenas $2 \%$ não.

b) Quando questionados se realizam ações com foco na sustentabilidade, destaca-se atividades como a coleta seletiva de lixo, a destinação adequada de resíduos tóxicos, tais como solventes, produtos de limpeza e cartuchos de tinta, controle de consumo de papel, água e energia.

c) Contudo, o que chama atenção é que boa parte dos empresários (MPE) não possuíam o hábito de utilizar matérias-primas ou materiais recicláveis no processo produtivo, cerca de $(51,7 \%)$.

O estudo ainda salientou que, por meio desses dados foi possível constatar a importância de incorporar nas MPEs práticas de gestão e estratégias de mercado que conceituem aspectos e elementos da sustentabilidade. E é nesse contexto que a LR pode configurar-se como elemento agregador orientando a inovação através de práticas e ações sustentáveis nas MPEs.

Conforme a base conceitual a respeito da LR encontrada, observou-se que a mesma (LR) pode trazer inúmeros benefícios a uma empresa, sobretudo pela eficiência no uso dos recursos e a proteção ao meio ambiente, proporcionando também o desenvolvimento de práticas sustentáveis. Lacerda (2002) salienta que são três os principais motivos que levam o aumento de praticabilidade da LR nas empresas: as questões ambientais, a concorrência associada à diferenciação de produto e a redução de custos.

Consequentemente, se permite refletir que a LR, além de contribuir para o sucesso organizacional, pode proporcionar um melhor suporte no Pós-venda, Pós-consumo e no gerenciamento da cadeia produtiva, sendo inúmeras as oportunidades gerenciais e estratégicas que ela é capaz de propiciar.

A análise SWOT é uma ferramenta estratégica que permite um estudo simplificado das forças e fraquezas (análise interna), oportunidades e ameaças (análise externa) voltadas a uma empresa. Dessa forma, para análise do cenário interno e externo da LR, foram levadas em conta as referências bibliográficas, aspectos da lei da PNRS e os dados do SEBRAE na tentativa de elucidar possíveis fatores que poderiam ser considerados como forças, fraquezas, ameaças $e$ oportunidades da LR, com o intuito de verificar a sua viabilidade como elemento que oriente a inovação nas MPEs.

A Figura 1 sintetiza os elementos que foram avaliados como forças, fraquezas, ameaças $e$ oportunidades da LR tendo como ênfase a sua aplicabilidade nas MPEs; e na sequência, descreve-se cada um dos itens contidos na imagem. 
Figura 1 - Análise SWOT da Logística Reversa

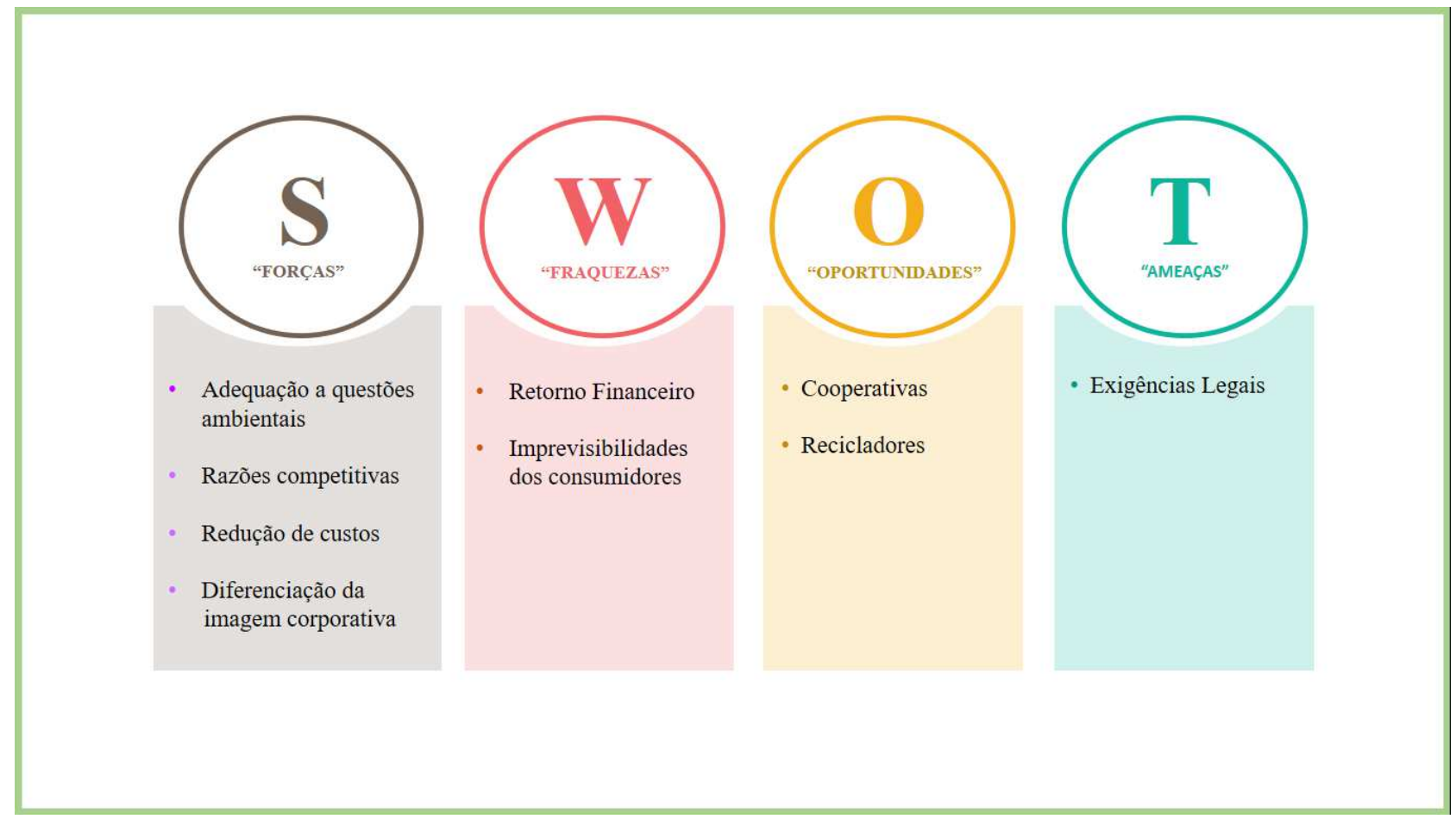

Fonte: Elaborado pelos autores desse artigo (2019)

Destaca-se como "forças" da LR:

- Adequação a questões ambientais: Fomenta nas empresas a preocupação sobre os impactos que seus produtos podem causar no meio ambiente e, consequentemente, na sociedade, uma vez que o principal objetivo ecológico da LR consiste no planejamento de ações empresariais com o intuito de contribuir com a sociedade por meio do incentivo à reciclagem de materiais, a elaboração de projetos para reduzir os impactos ao meio ambiente, entre outros.

- Razóes competitivas: Desenvolve vantagens competitivas diante dos concorrentes por meio de garantias de políticas liberais de retorno de produtos que fidelizam os clientes, posto que estes demandam, cada vez mais das empresas, atitudes "ecologicamente corretas".

- Redução de Custos: A reutilização e aproveitamento de materiais fornecem ganhos que podem estimular o desenvolvimento de novas iniciativas e aplicação de esforços para aprimorar o processo de LR, além de ajudar a reduzir os custos operacionais. Segundo Leite (2009), a reciclagem de latas de alumínio, por exemplo, gera uma redução de energia elétrica de $95 \%$, sendo que para sua fabricação esta representa $70 \%$ do custo.

- Diferenciação da imagem corporativa: Possibilidade de usar a LR de modo estratégico, principalmente de marketing, criando uma boa imagem para a empresa, além de poder contribuir para o desenvolvimento das comunidades em que estão inseridas. 
Em relação às “fraquezas” observadas na LR:

- Imprevisibilidade dos consumidores: Por mais que se tenha conhecimento sobre o tempo de vida de determinados produtos, não é possível prever quando o consumidor irá utilizá-lo e descartá-lo.

- Retorno Financeiro: Alcançado apenas no longo prazo, além da demanda em pesquisas no intuito de melhorar de forma contínua os processos produtos, atendendo não só as exigências do mercado, mas também da legislação.

A respeito das "oportunidades", considerou-se o fomento de novas atividades econômicas como as cooperativas de catadores de lixo e recicladores. As cooperativas geram renda $e$ melhores condições de vida para a sociedade como um todo, tendo em vista que se baseiam nas questões ambientais e preservação do meio ambiente fazendo a seleção de materiais descartados de forma indevida, que podem ser ainda reaproveitados ou reciclados, cabendo aos recicladores essa função.

Por fim, identificou-se como possível "ameaça" às exigências/disposições legais. A lei estabelece a responsabilidade compartilhada na destinação dos resíduos. Logo, cada integrante da cadeia produtiva tem um papel importante e uma função específica a desempenhar e, se um desses não cumprir com sua obrigação, pode comprometer e tornar o processo reverso incipiente (quanto ao manejo e controle adequado dos resíduos sólidos).

Por meio de uma perspectiva da literatura e do que tem sido produzido a respeito da temática em estudo, a análise SWOT mostra apenas alguns elementos que podem gerar impactos no processo de inovação.

Sua necessidade e a importância de sua aplicação são perceptíveis não só por intermédio dos dispositivos legais, os quais atestam como uma ferramenta moderna e imprescindível $e$ até mesmo inovadora para a gestão dos resíduos sólidos, como pela literatura acadêmica, que demonstra por meio de pesquisas e exemplos a aplicabilidade e os retornos mercadológico e socioambiental das práticas da LR, sobretudo pela perspectiva de ser uma prática inovadora para as MPE.

\section{Considerações Finais}

Através da análise realizada, foi possível compreender que, se bem gerenciada e direcionada estrategicamente, a LR nas MPE pode fomentar o desenvolvimento de práticas e atividades sustentáveis que geram bons retornos à empresa, principalmente relacionados ao aspecto financeiro, pela redução de custos por meio de atividades como a reciclagem e a reutilização de matérias. A análise proporcionou alcançar um resultado mais objetivo sobre a compreensão da LR servir de alicerce para práticas inovadoras nas MPE brasileiras, pois, o desenvolvimento de processos e atividades oriundas da LR introduzem o desempenho e a busca pela inovação em empresas desse porte, que não costumam ter práticas e ações sustentáveis.

A questão norteadora conduziu toda a argumentação e desenvolvimento do trabalho, possibilitando elucidar informações sobre como a LR pode orientar a inovação nas MPE, o que também, serviu para evidenciar a LR como um processo gerencial adaptável e passível de aplicação em qualquer segmento e tipo de empresa. 
Assim, conclui-se que, em termos financeiros, é possível reduzir custos operacionais, uma vez que a LR permite que a empresa tenha vantagem competitiva impactando positivamente não só em aspectos econômicos, mas principalmente, nos aspectos socioambientais. Também pode proporcionar um melhoramento da imagem no mercado, aumento da competitividade, otimização dos processos produtivos e reaproveitamento dos produtos do Pós-consumo e Pós-venda, bem como ser uma ferramenta auxiliadora para o alcance da sustentabilidade.

As empresas também contribuem com a preservação ambiental seja reciclando ou fazendo o descarte correto do lixo, ou até mesmo reincorporando esse produto ao processo produtivo e outros. Tais medidas podem proporcionar a redução no custo com água, energia e insumos.

O estudo proporcionou uma percepção mais clara sobre o conceito de LR, suas possíveis forças, fraquezas, oportunidades e ameaças, quanto à sua aplicação nas MPEs. A busca por artigos com exemplos de pesquisas sobre empresas reais que utilizam a LR auxiliou na ampliação do entendimento do tema estudado. Nesse sentido, vale ressaltar que as empresas não perderão a capacidade de explorar os recursos naturais, contudo tal exploração deve ser feita de modo responsável e consciente, conforme preveem as leis ambientais, na legislação brasileira, e as condutas ambientais adotadas.

Apesar de a lei definir regras, o seu cumprimento não depende só dos empresários ou de uma consciência sustentável. É necessário desenvolver um processo articulado que envolva todos os agentes de forma integrada e em ação contínua. Assim, empresas, prefeituras, associações setoriais, fornecedores, clientes, cooperativas e recicladoras devem trabalhar em conjunto. O empreendedor sozinho pode não conseguir solucionar o problema ambiental oriundo do descarte feito de forma incorreta, principalmente, os micro e pequenos empresários, pois é um processo que demanda tempo, gerenciamento eficiente, recursos financeiros e até transferência de tecnologia.

As MPEs, em sua maioria, podem não dispor de recursos financeiros para desenvolver práticas elaboradas para o melhor gerenciamento dos resíduos sólidos, e até mesmo o processo reverso, contudo é possível desenvolver parcerias com outras empresas, ou terceirizar o serviço por meio de cooperativas e recicladoras. Posto isso, a LR cria uma oportunidade no mercado pelo fomento de atividades econômicas, como as cooperativas, que passam a ganhar maior destaque uma vez que desempenham, além dos aspectos ambientais, um trabalho de inserção social.

De modo geral, este estudo buscou mostrar que é possível as MPEs adotarem práticas sustentáveis objetivando a redução de custos e terem vantagem competitiva desde que haja motivação para a aplicação das premissas da LR, principalmente, pelo potencial socioeconômico que elas detêm, visto que são mecanismos constitucionais de distribuição de renda, redução de desigualdades sociais, além do grande potencial demonstrado em gerar novas oportunidades, bem como emprego e renda.

Espera-se com este trabalho que pessoas e, especialmente, as empresas de micro e pequeno porte, diante de um cenário de escassez de recursos naturais e crescente preocupação com as questões socioambientais, possam vislumbrar uma alternativa inovadora para geração de renda, vantagem competitiva, criação de uma imagem corporativa sustentável, ao adotar as práticas da LR, lembrando que o diferencial competitivo e inovador pode ser definido nos 
pequenos detalhes. E é por isso que a LR pode ser elemento agregador e orientador para que as MPE inovem na forma de gerenciar seus produtos e serviços.

\section{Referências}

BALLOU, Ronald H. Gerenciamento da Cadeia de Suprimento/Logística Empresarial. 5. ed. Porto Alegre: Bookman, 2006.

BRASIL. Lei n. 12.305/2010. Disponível em: http://www.planalto.gov.br/ccivil_03/_ato20072010/2010/lei/112305.htm. Acesso em: 18 jul. 2019.

BRASIL. Ministério do Meio Ambiente. Plano de Gerenciamento de Resíduos Sólidos: Instrumento de Responsabilidade Socioambiental na Administração Pública. Brasília. 2014. Disponível em: http://www.protegeer.gov.br/biblioteca/publicacoes/gestao-integrada-de-rsu/51plano-de-gerenciamento-de-residuos-solidos-instrumento-de-responsabilidade-socioambiental-naadministracao-publica. Acesso em: 22 set. 2019.

BRASIL. Lei Complementar n. 123/2016. Disponível em: http://www.planalto.gov.br/ccivil_03/leis/ lcp/lcp123.htm. Acesso em: 19 jul. 2019.

BRASIL. Ministério do Meio Ambiente. Política Nacional de Resíduos Sólidos. 2019. Disponível em: http:/www.mma.gov.br/responsabilidade-socioambiental/a3p/eixos-tematicos/gest\%C3\%A3oadequada-dos-res\%C3\%ADduos. Acesso em: 17 jul. 2019.

BRASIL. Ministério do Meio Ambiente. Catadores de Materiais Recicláveis. 2019. Disponível em: https://www.mma.gov.br/cidades-sustentaveis/residuos-solidos/catadores-de-materiais-reciclaveis. html. Acesso em: 28 set. 2019.

CRUZ, Rosane. O empreendedor no processo de inovação de pequenas empresas de software do Rio Grande do Sul. In: EGEPE-ENCONTRO DE ESTUDOS SOBRE EMPREENDEDORISMO E GESTÃO DE PEQUENAS EMPRESAS. Brasília. Anais... Brasília: UEM/UEL/UnB, p. 496-508. 2003.

DIAS, Reinaldo. Gestão ambiental: responsabilidade social e sustentabilidade. São Paulo: Atlas, 2007.

DIAS, Sylmara Gonçalves. O desafio da gestão de resíduos sólidos urbanos. Sociedade e Gestão. v. 11, n. 1, p. 16-20, 2012.

DRUCKER, Peter Ferdinand. Inovação e espírito empreendedor. São Paulo: Pioneira, 1986.

GIRARDI, Luiz Tadeu de Azevedo. Inovação e Criatividade nas Pequenas e Médias Empresas. FGV. Dissertação de Mestrado. Rio de Janeiro. Março, 2001.

GONÇALVES, Marilson Alves; TANAKA, Ana Karolina; AMEDOMAR, André de Azevedo. A destinação final dos resíduos sólidos urbanos: alternativas para a cidade de São Paulo através de casos de sucesso. Future Studies Research Journal: Trends and Strategies, v. 5, n. 1, p. 96-129, 2013.

LACERDA, Adriana dos Santos. MOURA, Denise. A Responsabilidade Socioambiental como Estratégia de Competitividade para as Organizações da Contemporaneidade. In: XII CONGRESSO NACIONAL DE EXCELÊNCIA EM GESTÃO \& III INOVARSE 2016. ISSN 19849354. Disponível em: http://www.inovarse.org/node/4723. Acesso em: 22 set. 2019. 
LACERDA, Leonardo. Logística Reversa: uma visão sobre os conceitos básicos e as práticas operacionais. Centro de Estudos em Logística - COPPEAD, 2002. p. 3.

LAKATOS, Eva Maria; MARCONI, Marina de Andrade. Fundamentos de metodologia científica. 5. ed. São Paulo: Atlas, 2003.

LEITE, Paulo Roberto. Logística Reversa: meio ambiente e competitividade. São Paulo: Prenctice Hall, 2009.

MAIA, Adriano Felipe da Silva Maia. Inovação em Micro e Pequenas Empresas: uma análise do caso brasileiro. Dissertação (Mestrado) em Economia, Universidade Federal de Uberlândia. UFU. 2012. Uberlândia - Minas Gerais, 2012.

MINAYO, Maria Cecília de Souza (org.). Pesquisa social: teoria, método e criatividade. Petrópolis: Vozes, 2001.

MOTA, Ana Elage Azevedo Simões et al. Desafios e oportunidades da Logística Reversa no contexto do Plano Nacional de Resíduos Sólidos. GEPROS. Gestão da Produção, Operações e Sistemas, Bauru, ano 10, n. 4, p. 55-67, out-dez/2015.

NOVAES, Antônio Galvão. Logística e gerenciamento da cadeia de distribuição: estratégia, operação e avaliação. 2. ed. Rio de Janeiro: Elsevier, 2004.

OCDE. Manual de Oslo. Diretrizes para Coleta e Interpretação de dados sobre Inovação. Traduzido pela FINEP. Rio de Janeiro, Edição 2005. Disponível em: https://goo.gl/2GRfu0 . Acesso em: 17 ago. 2019.

ONU. Transformando Nosso Mundo: A Agenda 2030 para o Desenvolvimento Sustentável. 2015. Disponível em: https://nacoesunidas.org/pos2015/agenda2030/. Acesso em: 22 set. 2019.

PEREIRA, Anderson Spolavori; WELZEL, Albert; SANTANA, Dalva Verônica Mendonça. Logística Reversa Aplicada a Resíduos Eletroeletrônicos: Estudo de Caso. Convibra. In: IX CONGRESSO VIRTUAL BRASILEIRO DE ADMINISTRAÇÃO. 2011. ISSN 2179-5967. Disponível em: http://www. convibra.com.br/upload/paper/adm/adm_3106.pdf. Acesso em: 24 set. 2019.

POZO, Hamilton; AKABANE, Getúlio Kazue; SILVA, Plínio Alves Mamprim da Silva. As barreiras que as Micro e Pequenas Empresas da Região de Bauru/SP enfrentam para implantar um programa de Logística Reversa. In: XVI ENGEMA-ADMINISTRAÇÃO DE EMPRESAS, v. 53, n. 5, p.442-453, 2013, São Paulo. Anais eletrônicos [...] São Paulo: ENGEMA, 2013.

ROCHA, Flávia Azevedo Dias da; SIMONETTI, Vera Maria Medina. Gestão de pequenas empresas e responsabilidade social. In: Congresso Nacional de Excelência em Gestão, 4., 2008, Rio de Janeiro. Anais eletrônicos [...] Rio de Janeiro: CNEG, 2008.

SANTOS, Jaqueline da Silva et al. Logística verde: conceituação e direcionamentos para aplicação. REGET. Santa Maria, v. 19, n. 2, p. 314-331, mai-ago. 2015.

SANTOS, Leonardo Lemos da Silveira; ALVES, Ricardo César; ALMEIDA, Kennedy Nunes Tavares de. Formação de estratégia nas micro e pequenas empresas: Um estudo no Centro-Oeste Mineiro. ERA - Revista de Administração de Empresas, São Paulo, v. 47, n. 4. p. 59-73, out/dez. 2007.

SCHUMPETER, Joseph Alois. A teoria do desenvolvimento econômico. São Paulo: Nova Cultural, 1988. 
SEBRAE - Serviço Brasileiro de Apoio às Micro e Pequenas Empresas. Em estudos e pesquisa. Taxa de Sobrevivência das Empresas no Brasil, 2011. Disponível em: http://www.biblioteca. sebrae.com.br. Acesso em: 17 jul. 2019.

SEBRAE - Serviço Brasileiro de Apoio às Micro e Pequenas Empresas. O que pensam as micro e pequenas empresas sobre sustentabilidade , 2012. Disponível em: http://www.sebrae.com.br/ sites/PortalSebrae/bis/o-que-pensam-as-empresas-sobre-sustentabilidade,bb7e438af1c92410VgnVC M100000b272010aRCRDf. Acesso em: 19 jul. 2019.

SEBRAE-SP - Serviço Brasileiro de Apoio às Micro e Pequenas Empresas (São Paulo). Anuário do trabalho na micro e pequena empresa: 2015. Disponível em: http://www.sebrae.com.br/Sebrae/ Portal\%20Sebrae/Anexos/Anuario-do\%20trabalho-na\%20micro-e-pequena\%20empresa-2014.pdf. Acesso em: 22 set. 2019.

TACHIZAWA, T.; ANDRADE, R. O. B. de. Gestão Socioambiental: estratégias na nova era da sustentabilidade. Rio de Janeiro, Elsevier, 2008.

TADEU, Hugo Ferreira Braga et al. Logística reversa e sustentabilidade. São Paulo: Cengage Learning, 2012.

TEIXEIRA, Rivanda Meira; NETO, Ana Teresa da Silva. Mensuração do grau de inovação de micro e pequenas empresas: estudo em empresas da cadeia têxtil-confecção em Sergipe. In: Congresso XXXV Encontro do Anpad (EnANPAD). Revista de Administração e Inovação, São Cristóvão: Universidade Federal de Sergipe, 2011.

TURCHI, Lenita Maria; MORAIS, José Mauro de. (org.). Políticas de apoio à inovação tecnológica no Brasil: avanços recentes, limitações e propostas de ações. 2017. In: IPEA INSTITUTO DE PESQUISA ECONÔMICA APLICADA. Disponível em: http://www.ipea.gov.br/portal/ index.php?option $=$ com_content\&view $=$ article\&id $=30774$. Acesso em: 22 set. 2019.

VERGARA, Sylvia Constant. Projetos e relatórios de pesquisa em administração, 3. ed. São Paulo: Editora Atlas, 2000.

WILLE, Mariana Muller; BORN, Jeferson Carlos. Logística Reversa: Conceitos, Legislação e Sistema de Custeio Aplicável. Revista eletrônica dos Cursos de Administração e Ciências Contábeis UniOpet, Curitiba, n. 8, 2013. ISSN 2175-5884.

ZANATTA, Paula. Gestão Ambiental e o Desenvolvimento Sustentável. Revista de Gestão \&

Sustentabilidade Social, Florianópolis, 6, n. 3, p. 296-312, out. /dez. 2017.

\section{Sobre os Autores}

\section{Yris Raquel Santos de Santana}

E-mail: yris_raquel@hotmail.com

Bacharel em Administração.

Endereço profissional: Instituto Federal de Educação, Ciência e Tecnologia - (IFBA) Campus Salvador. Rua Emídio dos Santos, s/n, Barbalho, Salvador, BA. CEP: 40301-015. 


\section{André Luís Rocha de Souza}

E-mail: profandre.ifba@gmail.com

Doutorado em Engenharia Industrial.

Endereço profissional: Instituto Federal de Educação, Ciência e Tecnologia - (IFBA), Campus Salvador. Rua Emídio dos Santos, s/n., Barbalho, Salvador, BA. CEP: 40301-015.

\section{Ângela Maria Ferreira Lima}

E-mail: angela.lima@gmail.com

Doutorado em Energia e Ambiente.

Endereço profissional: Instituto Federal de Educação, Ciência e Tecnologia - IFBA, IFBA - Campus Salvador.

Rua Emídio dos Santos, s/n., Barbalho, Salvador, BA. CEP: 40301-015.

\section{Márcio Luis Valença Araújo}

E-mail: maraujo.valenca@gmail.com

Doutorado em Modelagem Computacional e Tecnologia Industrial.

Endereço profissional: Instituto Federal de Educação, Ciência e Tecnologia da Bahia - IFBA, IFBA - Campus

Santo Amaro. $1^{\text {a }}$ Travessa São José, s/n., Bomfim, Santo Amaro, BA. CEP: 44.200-000. 